\title{
Perspectives on marine zooplankton lipids ${ }^{1}$
}

\author{
G. Kattner, W. Hagen, R.F. Lee, R. Campbell, D. Deibel, S. Falk-Petersen, \\ M. Graeve, B.W. Hansen, H.J. Hirche, S.H. Jónasdóttir, M.L. Madsen, \\ P. Mayzaud, D. Müller-Navarra, P.D. Nichols, G.-A. Paffenhöfer, D. Pond, \\ H. Saito, D. Stübing, and P. Virtue
}

\begin{abstract}
We developed new perspectives to identify important questions and to propose approaches for future research on marine food web lipids. They were related to $(i)$ structure and function of lipids, (ii) lipid changes during critical life phases, (iii) trophic marker lipids, and (iv) potential impact of climate change. The first addresses the role of lipids in membranes, storage lipids, and buoyancy with the following key question: How are the properties of membranes and deposits affected by the various types of lipids? The second deals with the importance of various types of lipids during reproduction, development, and resting phases and addresses the role of the different storage lipids during growth and dormancy. The third relates to trophic marker lipids, which are an important tool to follow lipid and energy transfer through the food web. The central question is how can fatty acids be used to identify and quantify food web relationships? With the fourth, hypotheses are presented on effects of global warming, which may result in the reduction or change in abundance of large, lipid-rich copepods in polar oceans, thereby strongly affecting higher trophic levels. The key question is how will lipid dynamics respond to changes in ocean climate at high latitudes?
\end{abstract}

Résumé : Une nouvelle approche a été développée afin d'identifier les questions importantes relatives aux lipides dans les réseaux alimentaires marins et pour suggérer de nouvelles perspectives pour les recherches futures. Celles-ci concernent (i) la structure et la fonction des lipides, (ii) les changements lipidiques durant les phases critiques du cycle biologique, (iii) le rôle des lipides comme marqueurs trophiques et (iv) l'impact potentiel du changement climatique. Le premier point touche le rôle des lipides dans les membranes, les lipides de réserve et la flottabilité et la question essentielle est de savoir comment les propriétés des membranes et des réserves sont affectées par les divers types de lipides? Le second point traite de l'importance des lipides durant les phases de reproduction, de développement et de repos, ainsi que du rôle des différents lipides de réserve durant la croissance et la dormance. Le troisième point porte

Received 3 November 2006. Accepted 19 July 2007. Published on the NRC Research Press Web site at cjfas.nrc.ca on 6 November 2007.

J19639

G. Kattner, ${ }^{2}$ M. Graeve, and H.J. Hirche. Alfred Wegener Institute for Polar and Marine Research, 27570 Bremerhaven,

Germany.

W. Hagen and D. Stübing. Marine Zoology, University of Bremen, 28334 Bremen, Germany.

R.F. Lee and G.-A. Paffenhöfer. Skidaway Institute of Oceanography, Savannah, GA 31411, USA.

R. Campbell and D. Müller-Navarra. Institute for Hydrobiology and Fisheries Sciences, University of Hamburg, 22767 Hamburg, Germany.

D. Deibel. Memorial University of Newfoundland, Ocean Sciences Centre, St. John's, NL A1C 5S7, Canada.

S. Falk-Petersen. Norwegian Polar Institute, 9296 Troms $\varnothing$, Norway.

B.W. Hansen and M.L. Madsen. University of Roskilde, Department of Life Sciences and Chemistry, 4000 Roskilde, Denmark.

S.H. Jónasdóttir. Danish Institute for Fisheries Research, Department of Marine Ecology and Aquaculture, 2920 Charlottenlund, Denmark.

P. Mayzaud. Centre National de la Recherche Scientifique - Institut National des Sciences de l'Univers (CNRS-INSU),

Observatoire Océanologique, Laboratoire d'Océanographie de Villefranche, 06230 Villefranche-sur-Mer, France.

P.D. Nichols. Commonwealth Scientific and Industrial Research Organization (CSIRO), Marine and Atmospheric Research, Hobart, Tasmania 7000, Australia.

D. Pond. British Antarctic Survey, Cambridge, CB30ET, UK.

H. Saito. National Research Institute of Fisheries Science, Yokohama 236-8648, Japan.

P. Virtue. University of Tasmania, Institute of Antarctic and Southern Ocean Studies (IASOS), Hobart, Tasmania 7001, Australia.

${ }^{1}$ From 19 to 22 September 2005, 19 scientists met at the Hanse-Wissenschaftskolleg (Hanse Institute for Advanced Study) in Delmenhorst, Germany, to discuss the importance of marine zooplankton lipids. Participants included scientists with backgrounds in lipid chemistry, biochemistry, plankton ecology, and physiology.

${ }^{2}$ Corresponding author (e-mail: Gerhard.Kattner@awi.de). 
sur les lipides pouvant servir de marqueurs trophiques qui sont des outils importants pour suivre les transferts des lipides et de l'énergie dans le réseau alimentaire. La question centrale est alors comment peut-on utiliser les acides gras pour identifier et quantifier les relations dans un réseau alimentaire? Au quatrième point, nous proposons des hypothèses concernant le réchauffement global qui pourrait avoir comme résultat une réduction ou un changement d'abondance des copépodes de grande taille riches en lipides dans les océans polaires, ce qui affecterait considérablement les niveaux trophiques supérieurs. La question essentielle est ainsi comment la dynamique des lipides réagira-t-elle aux changements climatiques dans les océans de haute latitude?

[Traduit par la Rédaction]

\section{Introduction}

Lipids have many important functions: as energy reserves, membrane components, hormones regulating various processes, and antioxidants, but also as buoyancy aids. Essential fatty acids, generally $n-3$ and $n-6$ polyunsaturated fatty acids, are needed in the diets of animals to ensure growth, survival, and successful reproduction. Investigations have shown the physiological importance of lipids in marine zooplankton during various critical phases, such as reproduction, early development, and dormancy. This lipid research builds on the pioneering studies of earlier researchers, including Ackman (1964), Lee et al. (1970), Sargent et al. (1977), and others.

The different structures and functions that lipids have in marine zooplankton are reflected by the variable abundance in individual species, ranging from a few percent in gelatinous zooplankton to more than $60 \%$ of dry mass in copepods (reviewed by Lee et al. 2006). In the different oceanic regimes from the tropics to high latitudes, zooplankton has developed specific lipid adaptations, which are reflected in a variety of lipid classes comprising the classical storage lipids (e.g., triacylglycerols and wax esters), but also less common lipids, like diacylglycerol ethers or phospholipids serving as depot lipids.

In the tropics, epipelagic zooplankton are generally lipidpoor because of the high turnover of biomass and high metabolic rates in these oligotrophic regions (Lee et al. 1971; Lee and Hirota 1973). In high-latitude oceans, in contrast, zooplankton - mainly calanoid copepods and krill - accumulate enormous lipid stores by converting the lipid-poor phytoplankton to huge lipid deposits, which signifies a major specialization in polar bioproduction (Kattner and Hagen 1995). Generally in regions where bloom phytoplankton production occurs, as in high and temperate latitudes and coastal and upwelling areas, wax-ester-storing species are dominant lipid-rich members of the zooplankton community, especially copepods. These lipid-rich copepods are a main food source for higher trophic organisms. Atlantic herring (Clupea harengus), for example, uses sequestered copepod lipids for overwintering and reproduction (Varpe et al. 2005). Thus, the availability of large amounts of certain phytoplankton via copepods is essential for the abundance and persistence of herring populations.

Lipid accumulation is crucial in many zooplankton taxa during their different life-cycle phases. Calanoid copepods can start to store phytoplankton lipids and to biosynthesize lipids de novo effectively from the late nauplii up to the adult stages. Several copepod and euphausiid species deposit large lipid stores, primarily wax esters, during spring- summer blooms, followed by descent and diapause in deeper waters (Sargent and Henderson 1986; Falk-Petersen et al. 2000; Lee et al. 2006). Lipid stores provide energy for maintenance during winter and may allow reproductive processes in late winter or spring. Some copepods are able to reproduce at depth during winter without feeding, whereas others are dependent on feeding and have aligned reproduction with the onset of the spring phytoplankton bloom.

The presence of a number of essential phytoplankton fatty acids in zooplankton lipids has shown the importance of different phytoplankton groups in zooplankton feeding. In addition, typical long-chain, monounsaturated fatty acids and alcohols are biosynthesized by herbivorous calanoid copepods, which are transferred up the food chain. These taxon-specific fatty acids have been successfully applied as trophic markers to reveal dietary relationships (Dalsgaard et al. 2003). The analysis of signature fatty acids has strongly benefited from the advent of modern capillary gas chromatography. Statistical analyses and modeling have contributed to advance our understanding of the lipid and fatty acid biochemistry of planktonic organisms and of trophodynamics.

Considering the future impact of climate change on marine ecosystems with emphasis on the critical interplay between phytoplankton and zooplankton development, one of the main questions is how lipid dynamics will be affected by global warming, especially in the extremely sensitive highlatitude oceans (Edwards and Richardson 2004). One possible consequence of climate warming is a shift in the dominance from lipid-rich zooplankton populations to lipidpoorer zooplankton species. This hypothesized substitution has broad and important implications for the energy flux towards higher trophic levels, including many important commercial fish species. Hypotheses are offered in view of different responses of the zooplankton communities to climate change.

In this perspective, we focused on (i) structure and function, (ii) critical life-cycle stages, (iii) trophic marker lipids, and (iv) potential impact of climate change on zooplankton lipids, which we considered as important for future research and where we identified major efforts necessary to enhance the knowledge on lipids in zooplankton research. This article does not only include biochemical and physiological aspects, but also opens an ecological perspective.

\section{Structure and function}

How are the properties of membranes and deposits affected by the various types of lipids?

The importance of lipids for the different zooplankton species varies greatly. Lipid content in zooplankton can 
range from a few percent dry mass (e.g., gelatinous zooplankton) to being the most abundant component present in many copepod species (Sargent and Henderson 1986; Lee et al. 2006). Lipids reported in marine zooplankton show considerable diversity; complex lipids include a range of polar lipids (phospholipids), as well as a variety of simple and complex neutral lipids, such as triacylglycerols, wax esters, diacylglycerol ethers, and sterols. Hydrocarbons and other lipid classes may also be present. Polar lipids have been traditionally viewed as structural lipids in biomembranes, whereas neutral lipids are generally thought to have a storage role. However, recent studies have highlighted that specific phospholipids, especially phosphatidylcholine, have storage function in some crustacean species, including krill (Hagen et al. 1996; Mayzaud 1997), larval stages of lobster species (Jeffs et al. 2001), and anomuran crabs with lecithotrophic larval development (Kattner et al. 2003a). Storage lipids are strongly influenced by both energy requirements of the organisms and their trophic environment. However, knowing the overall structural composition of neutral lipids is not sufficient to determine their specific functions. The bulk of neutral lipids are catabolized to produce energy in form of ATP or channeled towards reproduction. However, considering the low mass density of lipids, they may also provide considerable positive buoyancy in a wide range of zooplankton organisms.

\section{Structural lipids}

The lipid bilayer of biomembranes determines their basic structure and is responsible, together with other constituents such as proteins, for their functional properties. Membranes differ in composition in various cell types, with phospholipid compositions correlating with membrane function. As an example, the ratio of phosphatidylethanolamine to phosphatidylcholine reflects compensatory mechanisms that allow maintenance of physical-chemical membrane properties with changing temperatures. Phosphatidylserine can be found at elevated levels in specific organs (e.g., gills), while phophatidylinositol is present at high levels in nerve tissue (reviewed by Chapelle 1986). Thus, phospholipid composition relates to specific requirements of different cells and tissues, and a specific fatty acid composition of phospholipids is necessary to maintain membrane function. The contents of $20: 5(n-3)$ and 22:6(n-3) fatty acids vary in freshwater copepods depending on the ambient temperature (Farkas 1979). Since the phase transition temperature of phospholipids with these highly unsaturated fatty acids is not markedly lower than that with fatty acids with fewer double bonds, the previously implied importance of these polyunsaturated fatty acids in the regulation of membrane fluidity at cold temperature has been questioned (reviewed by Stillwell and Wassall 2003).

There are considerable data on lipids in the plasma, mitochondrial, and nuclear membranes of terrestrial animals, but almost no information is available on membrane lipids in marine zooplankton. Thus, investigations of different organs, cells, and membranes are greatly needed to extend our understanding of the structure and function of these lipids in marine zooplankton.

Innovative research is required to determine the structural and functional roles of specific lipid classes. It needs to be clarified whether a particular lipid type has primarily a certain membrane function or whether it is a structural membrane component. One approach to help understand the structurefunction relationship is to determine lipid and fatty acid profiles at the molecular (so-called molecular species) level. Coupling molecular taxonomic approaches with lipid profiling and chemotaxonomy using modern statistical packages will greatly enhance our understanding of lipid dynamics.

\section{Storage and metabolic lipids}

The large body of research on the content and composition of lipids stored by marine zooplankton has recently been reviewed (Lee et al. 2006). Again, it often remains unclear why organisms rely on a certain lipid class for storage. In contrast with triacylglycerols, wax esters seem to serve as long-term energy stores in herbivorous zooplankton, especially those from higher latitudes, which spend periods of food scarcity in a resting stage; however, this hypothesis is still under discussion. Total lipids of calanoid copepods are composed of up to $90 \%$ wax esters. In the herbivorous Calanus species, these wax esters consist of considerable amounts of the long-chain monounsaturated fatty acids and alcohols 20:1(n-9) and 22:1(n-11), as well as of fatty acids of dietary origin. In North Pacific Neocalanus species, however, the important 20:1(n-9) component is exchanged by 20:1(n-11) (Saito and Kotani 2000). A reason for this difference is yet to be ascertained. Wax esters of smaller species, which are not purely herbivorous, usually contain shorterchain moieties (14:0 and 16:0).

Triacylglycerols are widely used storage lipids in zooplankton species that remain active throughout the year. Species such as Calanus propinquus, Calanus simillimus, Euchirella rostromagna, and Eucalanus bungii store high amounts of triacylglycerols. The primarily herbivorous Antarctic $C$. propinquus has developed a very effective fatty acid biosynthesis by producing long-chain monounsaturated fatty acids comparable with wax-ester-storing copepods; however, it is even more efficient by elongating the 20:1(n9) fatty acid to 22:1(n-9) (Hagen et al. 1993). Usually, this 22:1 fatty acid is either absent or only found in very small amounts in marine zooplankton organisms.

An unusual storage lipid, diacylglycerol ethers, is used by the pteropod Clione spp. (Phleger et al. 1997; Kattner et al. 1998; Böer et al. 2005). This lipid has high amounts of oddchain fatty acids that are apparently synthesized de novo, but information is lacking on the biosynthetic pathway of these fatty acids. This storage of diacylglycerol ethers is considered to be ancestral. However, it is still unclear whether the accumulation of odd-chain fatty acids incorporated into this type of lipid has any specific advantages (e.g., very efficient utilization of food, antibiotic activity) over triacylglycerol storage.

In addition to their general role as important components in biomembranes, phospholipids, specifically phosphatidylcholine, appear to serve for storage in specific taxa. To date, this has been observed in Antarctic and Arctic euphausiids and in the planktonic postlarvae of the spiny lobster (Jasus edwardsii). In lobster larvae, the phosphatidylcholine stores are apparently catabolized to satisfy energetic demands during the horizontal migration of the nonfeeding puerulus larvae (Jeffs et al. 2001). In some polar euphausiids, phosphati- 
dylcholine accumulates simultaneously with increasing lipid levels (Hagen et al. 1996). This has led to the hypothesis that phosphatidylcholine can serve as a supplementary depot lipid. In a study by Stübing (2004), histochemical analyses of Euphausia superba revealed extensive lipid storage, both neutral lipids and phospholipids, in tissue surrounding the hepatopancreas. In these euphausiids, most of the phospholipids were found in the free form (i.e., not incorporated into membranes). It is not clear whether this storage phosphatidylcholine is mobilized for energy production or rather held aside as "structural store" (i.e., for the rapid synthesis of cell membranes during periods of enhanced growth). The unique life cycle of euphausiids, which involves frequent molting, might imply a particular need for such depots. The ecophysiological advantages of phosphatidylcholine storage in euphausiids are still not understood.

\section{Buoyancy}

In contrast with proteins and carbohydrates, lipids have a lower density than seawater and provide positive buoyancy for many zooplankton species. Small differences among the specific densities exist between different lipid classes (Lewis 1970). There is an ongoing discussion on the role of lipids for buoyancy, since some studies have shown that copepod species are still rich in lipids after diapause in winter, and thus lipid utilization is only small (Jónasdóttir 1999). Therefore, it is hypothesized that the primary role of lipids in some species is to ensure their motionless position at depth to reduce the risk of predation (Visser and Jónasdóttir 1999).

Modeling the effects of lipids on the mass density of zooplankton suggests that very small changes in the total amounts of lipids translate to very large changes in buoyancy properties (Campbell and Dower 2003). For instance, changes of $2 \%-3 \%$ in wax esters can result in ascent or descent rates attributable to buoyancy on the order of one body length per second. Moreover, since lipids (and most other organic compounds) are more compressible than seawater, neutral buoyancy will not be stable at most depths. Lipids also have a larger thermal expansion than seawater, and thus, temperature may play an important role. To understand the role of lipids in buoyancy as it relates to pressure, temperature, and salinity, there is a need to measure density, compressibility, and thermal expansion of different lipid classes in live individuals.

Since buoyancy properties are highly sensitive to the relative proportion of lipids, they may represent a buoyancy problem, rather than a buoyancy aid. However, observations of live plankton show that quasineutral buoyancy occurs. Given the energetic and structural uses of lipids (i.e., the need to maximize energy stores and physiological capabilities), it is known that other mechanisms such as ionic regulation are used to control buoyancy, perhaps in combination with lipids.

\section{Critical life-cycle phases}

\section{What is the role of lipids during growth and dormancy?}

During various critical phases, such as egg production, early development, gonad maturation, and diapause, zooplankton have requirements for a variety of specific lipids.
Examples are polyunsaturated fatty acids, particularly 20:5(n-3) and 22:6(n-3), and cholesterol; vitamins $\mathrm{E}$ and $\mathrm{K}$ are also required as precursors to bioactive compounds. Saturated and monounsaturated fatty acids tend to be utilized as metabolic energy reserves, although they are present in variable amounts in membranes.

Based on the source of lipid used in reproduction, there are two broad groups of zooplankton: $(i)$ those that are independent of food intake for reproduction but utilize lipid stores (e.g., Calanus hyperboreus and Neocalanus plumchrus) and (ii) those that require food during reproduction (e.g., Calanus finmarchicus and Euphausia superba). Some species belong to both groups, depending on the time of reproduction (e.g., Neocalanus tonsus and Euphausia crystallorophias) (Lee et al. 2006). Other species (e.g., Calanus glacialis) do not strictly require food during reproduction, but egg production is strongly enhanced when food is available (Hirche and Kattner 1993).

For studies on this topic, readily accessible model genera, such as Acartia, Calanus, Oithona, and Euphausia, can be used, since they represent different strategies to deal with critical phases in their life cycles. Acartia spp., which belong to a complex zooplankton group with many neritic species that often produce diapause eggs, are especially amenable to laboratory experimentation. In addition, fjord populations of Calanus spp. are easily accessible and should be considered for diapause studies. The more oceanic C. hyperboreus would be an ideal candidate for those studies, as this species goes into diapause as copepodite stage for the first 2 years with no reproductive costs, whereas during the third year it matures and reproduces.

In addition, we suggest future investigations to focus on gene regulation responsible for the production of lipoproteins and vitellins, which have important roles in zooplankton reproduction and embryonic development. Molecular tools are now available to launch such studies.

\section{Reproduction and early development}

During egg production (gonadogenesis and oogenesis), there is a conversion of storage lipids (wax esters and triacylglycerols) and (or) dietary lipids into phospholipids needed to form male and female gonads, and lipid droplets and yolk lipovitellin are accumulated in the developing ovary and oocytes. Phospholipids are associated with egg yolk lipovitellins, which are used to form membranes and other cell constituents in the developing embryo. There are different concentrations of lipid droplets and lipovitellin in eggs depending on how soon after hatching the larvae start feeding (Lee et al. 2006).

If reproduction is to be successful, a number of specific lipids is required. Reproductively active females have particularly high requirements for polyunsaturated fatty acids, since viable eggs depend on specific biochemical provisioning. For embryonic development, lipids are used to provide energy and to form biomembranes. Comparatively little has been published on the lipid and fatty acid compositions of zooplankton eggs, particularly from zooplankton collected in the field. Further work is also needed on the contribution of dietary and somatic resources for egg production and on the link among lipid composition of eggs, hatching success, and survival of nauplii to the first feeding 
stages. Experimental studies are necessary on specific lipid requirements (food quality) that allow the production of healthy larvae (vitellogenesis and embryonic development). Recent techniques using labeled fatty acids in microcapsules and a labeled diet (Graeve et al. 2005) should provide new information on allocation of specific lipids in the different phases of the reproductive process.

During early developmental stages, when growth is rapid, polyunsaturated fatty acids are required to assemble membranes. Early zooplankton larvae depend on egg lipid reserves, but these developing nauplii soon become dependent on dietary lipids. An important question is how food availability and quality during early phases affect development and survival. There is a general need for comprehensive field studies on lipid composition of zooplankton diet, including both autotrophic and heterotrophic food sources, and the seasonal variability of these lipids. It would be useful to have information on the lipid composition of microheterotrophs and larval stages that are important in the diet of some omnivorous zooplankton species.

Euphausiids represent a special group, which often have prolonged and complex larval developmental phases, where different lipids play critical roles. Euphausiid eggs need to be provisioned with sufficient reserves to fuel metabolism and provide the necessary structural lipids to sustain development. Eggs do not hatch immediately on release, and the larvae do not feed immediately after hatching (Fevolden 1980). In some species like E. superba, the eggs even sink to great depth, and the early stages exhibit an extensive developmental ascent (Marr 1962).

Important questions include what are lipid requirements during winter, and what is the importance of lipids derived from shrinkage, cannibalism, microheterotrophs, and icealgae during this season? Further work is needed to understand the significance of lipids in gonad maturation, molting, and mating. In addition, the role of zooplankton groups other than crustaceans (e.g., cnidarians, molluscs, chaetognaths, and tunicates) in the synthesis, metabolism, and trophic transfer of lipids in the marine food web needs to be established.

\section{Resting phases}

Different zooplankton groups employ a variety of overwintering strategies. Dormancy (e.g., diapause or quiescence), occurring during unfavorable environmental conditions, is a widespread adaptation in planktonic crustaceans. During dormancy, an organism ceases development and reduces metabolism (Dahms 1995). There are two types of diapause: one is restricted to certain developmental stages, which is often closely associated with reproduction (Hirche 1996), and the second comprises the resting eggs. The role of lipids for each strategy is not clearly identified and is still speculative.

Lipid metabolism can change before, during, and after diapause. In many species, gonads mature towards the end of diapause, and eggs may be released by the females without additional food intake. This enables several diapausing copepod species to reproduce in winter and early spring before phytoplankton becomes available. They utilize lipids accumulated during the previous summer season (Conover and
Siferd 1993; Hirche and Niehoff 1996; Hagen and Auel 2001). Their eggs are characterized by large yolk and many lipid droplets, which allow development without feeding through at least the first nauplii stages, and in some cases up to the first copepodite stage. In other species, only the first phase of vitellogenesis takes place during diapause, with further oocyte maturation fuelled by feeding (Lee et al. 2006).

There are probably different lipid requirements for different life-history strategies. To include most diapausing copepod species, it will be necessary to consider the food environment of the previous summer and ultimately interannual and large-scale variability in food abundance. In addition, zooplankton itself may also regulate lipids because of conversion and accumulation of specific compounds. Analyzing and comparing the lipid dynamics of the same copepod species in diapausing, deep-dwelling specimens, as well as in those in upper waters during the reproductive period, will give an indication of lipid needs during gonadogenesis.

Three types of resting eggs (quiescent subitaneous, diapause, and delayed hatching eggs) can be produced by many zooplankton species, which differ in their mode of development. Subitaneous eggs hatch quickly, but can become quiescent in response to adverse conditions. Development of the quiescent eggs resumes when the conditions are restored (e.g., Katajisto 2003). In contrast, diapause eggs have an obligatory refractory phase, during which development does not resume even under favorable conditions (Grice and Marcus 1981). Unlike postrefractory diapause eggs, which may hatch soon after they perceive the appropriate environmental cues, nauplii emerge from delayed-hatching eggs only gradually over an extended period of time (Chen and Marcus 1997). It has recently been documented that density as well as amino acid and lipid content are higher for diapause as compared with subitaneous eggs for Centropages tenuiremis (Wang et al. 2005). However, the specific composition of lipids in diapause eggs is unknown. Diapausing eggs exhibit severely reduced metabolic rates and may remain viable for many years. It has been proposed from culture studies with Acartia tonsa that during quiescence the eggs retain metabolic activity although at a low level (Nielsen et al. 2006), causing depletion of free amino acids and fatty acids (Drillet et al. 2006). Consequently, egg viability decreases faster with time for these eggs than for diapause eggs.

Owing to the extremely scarce knowledge on lipids in resting eggs, studies are needed on the composition and role of lipids in diapausing and quiescent subitaneous eggs, as well as on metabolic differences among these different types of eggs. Questions with regard to critical lipid levels and specific lipid requirements to ensure successful overwintering and spring reproduction have to be clarified.

\section{Trophic marker lipids}

\section{How can fatty acids be used to identify and quantify food web relationships?}

A major aim of trophic studies is to evaluate the amount of organic matter that becomes available from lower trophic levels (i.e., phytoplankton and zooplankton) to higher 
trophic levels such as fish, birds, and mammals. A further aim is to enhance our knowledge on biogeochemical cycles with respect to food web interactions. Such an evaluation requires information on standing stocks of phytoplankton and zooplankton in connection with rates of growth and production and pathways of material flow through the food web. In addition, the transformation efficiency of organic matter, synthesized by phytoplankton, into body tissue of herbivorous zooplankton, hence the transfer of primary to secondary production, needs to be studied under various environmental conditions. The concept of fatty acids as trophic markers has been established during the last 30 years and is reviewed in detail by Dalsgaard et al. (2003).

For an improved understanding of the fate of lipids in marine food webs, further investigation of plankton is needed to obtain additional specific trophic markers. Such markers should be stable during their transfer through the food chain. Unfortunately, stable markers are probably not available, and hence, a combination of different methods, such as fatty acid trophic markers, stable isotope ratios, sterols, pigments, gut contents, and genetic markers, as well as lipophilic anthropogenic substances (e.g., PCB), appears to be more useful to overcome problems that may arise using only a single method. Trophic marker analyses in combination with modern statistical tools can also improve our understanding of food web interactions.

\section{Dietary and de novo fatty acids}

Fatty acid trophic markers are mostly used in a qualitative way to reveal information on feeding preferences and the ingestion of food items. Studies tracking marker lipids and fatty acids through the marine food web and organisms using detailed quantitative biochemical analysis are less common. Harvey et al. (1987) tried to follow the fate of phytoplankton fatty acids from the uptake by copepods through to egestion. A promising approach in the evaluation of the fate of lipids during feeding is the use of labeled specific fatty acids in diets (Graeve et al. 2005).

Polyunsaturated $n-3$ fatty acids originating from phytoplankton can be deposited unchanged in the polar and neutral lipid fractions of higher trophic organisms. However, considerable loss of information may occur because of rapid digestion and biosynthetic alteration of lipids, especially at higher trophic levels. Another unsettled issue concerns the ability of some zooplankton species (e.g., protozoans) to synthesize polyunsaturated fatty acids de novo, while crustaceans do not synthesize these fatty acids. Some protozoans can also convert phytoplankton shorter-chain polyunsaturated fatty acids to longer-chain ones (Ederington et al. 1995) and thus may be an important source of essential fatty acids to Protozoa-consuming zooplankton.

It is well established that certain fatty acids found in zooplankton species originate from phytoplankton diets (Graeve et al. 1994), such as palmitoleic acid, 16:1(n-7), $\mathrm{C}_{16}$ polyunsaturated fatty acids (diatom markers), and octadecatetraenoic acid (18:4(n-3); flagellate marker). A very interesting fatty acid that occurs in high amounts in the dinoflagellate Prorocentrum minimum is octadecapentaenoic acid (18:5(n3); Mayzaud 1976). Although already reported as a marker in the past, to date very little is known about the fate of this fatty acid in the food web (Ghioni et al. 2001). Besides phytoplanktonic fatty acids, fatty acids and alcohols (of wax esters) synthesized de novo by herbivorous zooplankton, such as long-chain monounsaturates with 20 and 22 carbon atoms, are used to study trophic relationships especially in zooplanktivorous fish (e.g., Sargent and Henderson 1986). However, little research has been conducted using these monounsaturated trophic markers on other taxa, which also feed on copepods such as ctenophores and decapods (Crustacea).

Future studies on fatty acid trophic markers should place greater emphasis on the evaluation of lipid and carbon mass balances in marine zooplankton. Studies with isotope tracers $\left({ }^{15} \mathrm{~N},{ }^{13} \mathrm{C}\right)$ may provide new insights on carbon flux into individual lipid and fatty acid components. However, a range of environmental factors may influence such parameters. Thus, results obtained using these methodologies require careful interpretation. To model the lipid transfer through food webs, well-defined predator-prey relationships should be selected. There is also a need to estimate the time span from production to consumption of trophic markers in combination with the impact of mixed diets. Of particular importance is the need to perform experiments to investigate the transfer of lipids and fatty acids during growth and reproduction, egg production and associated lipid accumulation, and subsequently utilization by larvae.

In addition, environmental and developmental variability will affect the physiology and thus lipid composition of zooplankton. It is of great importance to carefully select specimens for lipid analyses with regard to developmental stage and nutritional status. By using randomly selected specimens, which is usually the case, marker signatures will be blurred and important information may be lost. Lipid determination on individual, exactly biologically characterized specimens (with regard to stage, sex, gonad development, oil sac size, etc.) has to be done in future, and methods are already available or in progress.

Most of our current knowledge is derived from a small group of model zooplankton taxa, including Copepoda, Euphausiacea, and Pteropoda. With regard to research using trophic marker fatty acids and hence with the transfer of energy in the form of lipids through the food web, further screening of other marine zooplankton groups, particularly smaller copepod species and other less explored groups should be conducted. Small zooplankton species can have a specific lipid pattern (Kattner et al. 2003b; Lischka and Hagen 2007) and may considerably contribute to the zooplankton communities. Analysis of a broader zooplankton spectrum will provide new biochemical signatures including lipid profiles and other end products that could be important for the understanding of lipid production by marine zooplankton. This approach is also needed to reveal new information on the ecological relevance of zooplankton species on general lipid compositions and biosynthetic pathways.

Examination of species-specific spatial and seasonal variability in lipid composition, together with investigations of non-lipid markers and stable isotopes, may also provide new insights into the life history, strategy, and feeding behavior of single species, as well as seasonal variability of lipids. The opportunity to link field-based signature lipid studies to 
wider environmental programs, including climate change and climate variability, also needs to be pursued.

\section{Statistics and modeling}

Over the last two decades, the statistical analysis of trophic interactions using fatty acid profiles has moved from descriptive to more sophisticated models. The introduction of multivariate statistical analyses of fatty acid profiles, such as correspondence or principal component analyses, redundancy and discriminant analyses (Budge et al. 2002), and SIMCA pattern recognition analyses (Vogt and Knutsen 1985), has opened new avenues to address more complex interactions with higher trophic levels.

In related studies, considerable progress has been made using signature lipid profiles to investigate marine mammals, including seals, with both the fatty acid signature approach and more recently a refined quantitative fatty acid signature approach, which takes into account the differential catabolism of some prey markers (Iverson 2004). Such developments have advanced the lipid signature quality, although there have been critiques of some of these recent developments. Principal component analysis and other similar techniques are now routinely used for phytoplankton and zooplankton fatty acid profile analyses. Modeling signature lipid profiles of zooplankton has seldom been used to date, although such an approach seems very promising.

A problem in lipid research is the availability of data on lipid and fatty acid compositions obtained during the past two or three decades. It is often difficult to get access to many of these data sets, because they are hidden in the "gray literature" or are still unpublished. The maintenance of a consistent database will be helpful to evaluate data on lipid and fatty acid compositions over long periods. A combination of various data sets in a modern database with further statistical evaluation will help reveal trends on species-specific trophodynamics as well as spatial and interannual variations of lipids in zooplankton. There are several databases that are accessible and useful: the National Oceanographic Data Center (NODC, www.nodc.noaa.gov), PANGAEA (www.pangaea.de), and the Ocean Biogeographic Information System (OBIS). The first step towards an extensive, well-managed database is the establishment of a lipid information system (metadatabank) to keep the scientific community informed about existing data sets and research activities.

\section{Potential impact of climate change}

\section{How will lipid dynamics respond to changes in ocean climate at high latitudes?}

With regard to climate change, high-latitude ecosystems belong to the most sensitive regions on earth (Flato et al. 2000). They are also well known for their lipid-rich fauna. Over geological time scales, oceanographic climate changes have resulted in the evolutionary turnover of phytoplankton and zooplankton species because of modifying water masses and the gradients between them to create new habitats (Bradford-Grieve 2002). The history of climate and plankton in high latitudes has shown that diatoms and copepods have evolved during a period of global cooling, when polar ice caps were formed, and when marine production became more seasonally pulsed (largely since the CretaceousTertiary (K-T) extinction event 65 million years ago; Rigby and Milsom 2000). It is hypothesized that the present composition of the herbivore community, as well as the lipid synthesis, reflect not only the present climate variability but also the variation in climate observed over past centuries and millennia.

The ice-covered seas are some of the most dynamic areas in the world's oceans, with large fluctuations in ice cover occurring on time scales of hours, days, seasons, yearsdecades, centennials, or even longer. The Eurasian part of the Arctic Ocean and Nordic Seas was ice-free for a long period from 1690 to 1790 , similar to what we see today. This period of little ice was followed by a long period of heavy ice lasting from approximately 1790 until the 1930s. Large parts of the Barents and Norwegian seas were ice-covered in spring of 1966, while by 1995 most of those areas were icefree (Vinje 1999, 2001). Interannual and decadal oscillations in ice cover of the Arctic Ocean are related to meteorological events, such as the North Atlantic Oscillation, which occurs over periods of 7-10 years (Dickson et al. 2000).

Towards higher latitudes in the Arctic, the time window for the primary production cycle is narrowing because of seasonality of ice conditions and light (Zenkevich 1963). The present day seasonal cycle of diatoms and calanoid copepods in high latitudes depends on strong seasonality of ice cover and stratification, both of which will be reduced as the climate becomes warmer. Thus, climate change will likely have a large effect on the seasonal cycle of polar zooplankton. Carmack and Wassmann (2006) concluded that "The immense changes in climate forcing of the AO [Arctic Ocean] over relatively short evolutionary time scales, suggests that its ecosystems are capable of coping with further climatic changes even abrupt ones, but that the range and survival of individual species is less certain."

Some global circulation models predict an ice-free Arctic Ocean by 2100 (Johannessen et al. 2002). Thus, it is timely to reflect on possible effects of a changing polar ocean climate upon the lipid dynamics of phytoplankton and zooplankton taxa and populations, particularly since food web linkages are affected by ocean climate (Aebischer et al. 1990; Richardson and Schoeman 2004).

\section{Consequences for lipid dynamics}

The main differences between the Arctic Ocean and the Southern Ocean are their differing latitudes, resulting in fundamental environmental differences for phytoplankton and zooplankton. These variables include seasonal light and freshwater cycles, meteorological forcing, ice cover, and inorganic nutrient supply. The combined result of these latitudinally dependent differences is that phytoplankton and zooplankton production are more seasonally pulsed in the Arctic Ocean than in the Southern Ocean (Table 1). We argue that the stronger seasonal pulsing of phytoplankton in the Arctic Ocean (i.e., annual spring blooms of diatoms with peak abundance and short temporal duration) results in the dominance of the six large calanoid species, with Calanus hyperboreus, C. glacialis, C. finmarchicus, and Metridia longa representing more than $80 \%$ of total zooplankton biomass in the entire Arctic Ocean Basin (Thibault 
Table 1. A comparison of the present state of the Arctic and Southern oceans, including major zooplankton species (for further details refer to Lee et al. 2006).

\begin{tabular}{|c|c|c|}
\hline Parameter & Arctic Ocean Basin & Southern Ocean \\
\hline Latitude & $70-90^{\circ} \mathrm{N}$ & $50-75^{\circ} \mathrm{S}$ \\
\hline Weather & Low pressure, basin-type circulation & $\begin{array}{l}\text { Continental, with catabatic and circumpolar } \\
\text { winds }\end{array}$ \\
\hline Ice cover & Seasonal to permanent, multiyear & Seasonal, annual \\
\hline Freshwater source & Rivers & Glaciers \\
\hline Inorganic nutrients & Seasonally limiting & High nutrient - low chlorophyll region \\
\hline Phytoplankton bloom & Seasonally high peak but short & Seasonally lower peak but longer \\
\hline Zooplankton species diversity & Low & High \\
\hline $\begin{array}{l}\text { Zooplankton storing wax esters with } \\
\mathrm{C}_{22} \text { monoenes }\end{array}$ & $\begin{array}{l}\text { Calanus glacialis, Calanus hyperboreus, } \\
\text { Calanus finmarchicus }\end{array}$ & Calanoides acutus \\
\hline $\begin{array}{l}\text { Zooplankton storing predominantly wax } \\
\text { esters with short-chain moieties }\end{array}$ & $\begin{array}{l}\text { Metridia longa, Paraeuchaeta norvegica, } \\
\text { Pseudocalanus spp. }\end{array}$ & $\begin{array}{l}\text { Paraeuchaeta antarctica, Microcalanus } \\
\text { pygmaeus, Euphausia crystallorophias, } \\
\text { Thysanonessa macrura, Oncaea curvata }\end{array}$ \\
\hline $\begin{array}{l}\text { Zooplankton storing both wax esters } \\
\text { and triacylglycerols }\end{array}$ & Oncaea borealis & $\begin{array}{l}\text { Metridia gerlachei, Rhincalanus gigas, } \\
\text { Oithona similis }\end{array}$ \\
\hline Zooplankton storing glycerol ethers & Clione limacina & Clione antarctica \\
\hline $\begin{array}{l}\text { Zooplankton having no or unknown } \\
\text { lipid storage }\end{array}$ & $\begin{array}{l}\text { Oithona spp., Oikopleura spp., } \\
\text { Fritillaria borealis, Parasagitta } \\
\text { elegans, Eukrohnia hamata }\end{array}$ & Salpa thompsoni \\
\hline
\end{tabular}

et al. 1999). All these copepods store large amounts of wax esters, and the three Calanus species undergo seasonal diapause and contain substantial quantities of long-chain monounsaturated fatty acids and alcohols with 20 and 22 carbon atoms. Accordingly, we argue that the more modulated seasonal pulsing of the phytoplankton cycle in the Southern Ocean has resulted in a mixture of crustacean species storing either wax esters or triacylglycerols, and only Calanoides acutus undergoes diapause and contains longchain monounsaturated fatty acids and alcohols (Table 1). Given these fundamental differences, we predict differing responses of lipid dynamics to climate change in these two oceans.

In response to global climate change, variables in the ocean that may change are temperature, $\mathrm{pCO}_{2}$, nutrients, turbidity, sea ice extent-coverage (light), and mixed layer thickness (salinity, stratification). These changes have to be related to our key questions on future lipid dynamics in high-latitude zooplankton: How could changes of physical variables affect the species composition and phenology of phytoplankton? How would changes in phytoplankton species composition and abundance affect zooplankton communities? How will all of these changes affect the lipid dynamics of zooplankton and their predators?

The changes in long-term physical variables could lead to a warmer upper mixed layer of potentially $2-3{ }^{\circ} \mathrm{C}$ over the next century (Smetacek and Nicol 2005). Changing river impact could be pronounced, because the Arctic Ocean receives $10 \%$ of the global river runoff, and this freshwater flux is projected to increase between $20 \%$ and $70 \%$ by the year 2100 (Peterson et al. 2002). This could result in a reduced or prolonged (instead of strongly pulsed) production of diatoms rich in polyunsaturated fatty acids, along with a transition to a low-pulsed, microbial loop ocean (Legendre and Rivkin 2005). Falk-Petersen et al. (2007) postulate that warming of the Atlantic inflow and decrease in sea-ice cover in the southern Arctic Ocean may change the energy transfer: The ecosystem based on $C$. glacialis $-C$. hyperboreus feeding on diatoms favors specialized Arctic seabirds such as little auk (Alle alle), whereas a prolonged production period with a mixed diatom-dinoflagellate community results in a food chain based on C. finmarchicus - M. longa, leading, via Atlantic herring, to minke whales (Balaenoptera acutorostrata). In a warmer Arctic, Gradinger (1995) expected also a possible competition between the pure Arctic species $C$. hyperboreus and $C$. glacialis with $C$. finmarchcus. His scenario assumes a more productive ecosystem because of the reduced ice cover.

In addition, diatom production in an ice-free Arctic Ocean could shift spatially, with most of the production occurring along the outwelling plume fronts from the large Arctic rivers. This is in turn dependent on the nutrient supply, which is low in the Arctic Ocean and in the rivers entering the Arctic (Dittmar and Kattner 2003), but this may change when the huge permafrost areas melt. Such changes in the Arctic Ocean may also result in a shift in species and size composition of the copepod community, as described above, as well as in an increasing abundance of gelatinous suspension feeders (appendicularians) and gelatinous predators. If this occurs, the Arctic Ocean may become more Southern 
Ocean-like, with less intensive lipid synthesis and storage by zooplankton, reduced diapause or diminished abundance of diapausing species, and relatively lower lipid flux through the entire ecosystem. This may also include a shift in lipid class composition from high wax ester levels with longchain monounsaturated fatty acids and alcohols to an increased synthesis and storage of triacylglycerols.

We hypothesize that the above effects will be less pronounced in the Southern Ocean than in the Arctic Ocean. In the modern Southern Ocean, stratification is primarily due to salinity (Richardson and Schoeman 2004) as a result of the melting of annual sea ice. Since the reduction in ice extent will be limited, freshwater flux will not increase to a great extent in the Southern Ocean. Also, climate change will have different effects, because the Southern Ocean is a high nutrient - low chlorophyll (HNLC) region, with iron limitation south of the Polar Front and silicate limitation to the north.

A study conducted off the Antarctic Peninsula reported poor recruitment of krill (Loeb et al. 1997). Late spawning was associated with reduced regional sea-ice extent, whereas good recruitment was positively correlated to early spawning and extensive sea ice in the preceding winter. In contrast, salp abundance was negatively correlated to extensive sea ice. Salps belong to the gelatinous zooplankton, and they have very low lipid levels compared with krill and other crustacean zooplankton. Many areas may eventually change from a krill-dominated to a salp-dominated system. Implications of this shift in species associated with sea-ice extent may have a profound effect on the lipid availability to higher trophic organisms.

These changes may also have a strong impact on the aggregation behavior of large, lipid-rich zooplankton presently preyed upon by fish, seabirds, and marine mammals. The present seasonal migrations of some of the warm-blooded predators to polar regions to feed, reproduce, and nourish their young may cease. Reduced lipid contents of prey for higher trophic levels (e.g., seabirds) may be inadequate to support normal rates of breeding, hatching success, and recruitment (Wanless et al. 2005), even though lipid-poor prey may provide the same wet biomass of food as lipid-rich prey.

As the polar ocean climate is already changing, we need to use advanced technological tools to explore consequent changes in the abundance and distribution of zooplankton and related environmental variables. To comprehend the interactions of climate change with lipid dynamics of marine zooplankton requires long-term observations over a broad range of spatial and temporal scales, from individual genes to ocean basins and from hours to millennia.

First, we envision polar ocean monitoring over decadal periods similar to Roemmich and McGowan (1995) for the eastern Pacific Ocean off California. The proposed Arctic Ocean Observatory System contains all of the technical components important for polar ocean monitoring to document climate change, including zooplankton lipids. The plan includes a space component based on remote sensing, a surface component of ice-tethered platforms with meteorological and hydrographical sensors, an underwater component based on autonomous floats equipped with CTDs (probes for conductivity, temperature, and depth) and other instrumenta- tion, and a data integration component to relate empirical data to modeling studies. Details can be obtained at www.aosb.org/AOOS. Of particular importance for zooplankton lipid processes will be sampling frequency covering the range and rapidity of seasonal changes of environmental processes. The latter would include river discharge of freshwater, nutrients, and sediments to polar ocean continental shelves.

Second, it is important to determine the changes in plankton phenology (i.e., the presence and timing of cycles of organisms in relation to their environment). Observations of abundant species over regional spatial scales will contribute to a better understanding of the timing of population dynamics of phytoplankton and zooplankton and associated lipid processes. Field observations should include the following: species composition and abundance of phytoplankton, protozooplankton, and metazooplankton; enumeration of copepod stages; and quantification of total lipids, lipid classes, fatty acids, and alcohols in all copepodite and adult stages of abundant species (Table 1). Onboard process studies should include the quantification of ingestion and growth rates and associated lipid storage under differing environmental conditions. It will be important to separate life-cycle effects from influences of different food supplies when evaluating the lipid dynamics of high-latitude zooplankton.

Third, we strongly suggest the use of retrospective analyses. Cause and effect will be difficult to demonstrate unequivocally when trying to link polar ocean climate to lipid processes of zooplankton. Palaeo-oceanographic information will enhance our understanding of the impact of past climatic changes on zooplankton occurrence. We envision that combining past records with recent empirical observations on high-latitude zooplankton and lipids via numerical models will strengthen not only our understanding of important processes but will also permit a prognostic view of future trends as our planet undergoes climate change.

\section{Conclusions}

The questions presented reveal our limited knowledge of lipids in marine zooplankton. A major part of our expertise is based on planktonic crustaceans from high latitudes, which accumulate large amounts of lipids during their lifetime. The polar ecosystems are widely dependent on or are even driven by the accumulation of lipids because of the short pulses of primary production. The seasonality of food supply is the major driving force for animals to store lipids for survival of food-scarce periods and reproduction. The seasonality also signifies temperate regions, upwelling areas, and partially the deep sea, but is most pronounced in the icecovered high latitudes. In contrast, low-latitude tropical epipelagic zooplankton species do not deposit lipids because of the high metabolic turnover and the continuous feeding and rapid utilization of available food items for growth and reproduction. Hence, lipid studies are clearly of lower priority in the tropics as compared with other regions.

A number of interesting questions relate to changes in polar ocean zooplankton communities, such as reports of increases in the populations of lipid-poor gelatinous suspension feeders (e.g., salps and appendicularians). The 
impact of such dramatic changes in lipid content and composition on the respective predators requires thorough investigations. In addition, lipids and their role in smaller taxa (e.g., protozooplankton and cyclopoid copepods), which are important both within the zooplankton food web and the microbial loop, need to be addressed.

Work is also needed on the importance of zooplankton lipids during different life-history stages and how these lipids are affected by dietary quality and quantity. Information on lipid abundance, storage, composition, and metabolism of nauplii and early copepodite stages of almost all copepod species is nonexistent, despite the fact that their survival is of crucial importance for recruitment. Genetic regulation of lipid accumulation and metabolism, particularly during reproduction, is another important subject for future work.

Achieving this science will require an international effort to build a consensus of lipid research and to make a case to funding agencies and politicians regarding the importance of understanding the impact of climate change on the dynamics of these high-energy compounds in the sea. Enhanced knowledge of the lipid dynamics of zooplankton that serve as key drivers interlinking primary and secondary production (i.e., major pathways of carbon flow in the marine food web) will increase our ability to understand crucial adaptive processes to climate change and other anthropogenic influences.

\section{Acknowledgements}

We are grateful to the Hanse-Wissenschaftskolleg (Hanse Institute for Advanced Study, HWK), Delmenhorst, Germany, for hosting the workshop. We thank the HWK, the Deutsche Forschungsgemeinschaft (GZ: 4850/147/05), and the Alfred Wegener Institute for financial support.

\section{References}

Ackman, R.G. 1964. Structural homogeneity in unsaturated fatty acids of marine lipids - a review. J. Fish. Res. Board Can. 21: 247-254

Aebischer, N.J., Coulson, J.C., and Colebrook, J.M. 1990. Parallel long-term trends across four marine trophic levels and weather. Nature (London), 347: 753-755.

Böer, M., Gannefors, C., Kattner, G., Graeve, M., Hop, H., and Falk-Petersen, S. 2005. The Arctic pteropod Clione limacina: seasonal lipid dynamics and life-strategy. Mar. Biol. 147: 707717.

Bradford-Grieve, J.M. 2002. Colonization of the pelagic realm by calanoid copepods. Hydrobiologia, 485: 223-244.

Budge, S.M., Iverson, S.J., Bowen, W.D., and Ackman, R.G. 2002. Among- and within-species variability in fatty acid signatures of marine fish and invertebrates on the Scotian Shelf, Georges Bank, and southern Gulf of St. Lawrence. Can. J. Fish. Aquat. Sci. 59: 886-898.

Campbell, R.W., and Dower, J.F. 2003. The role of lipids in the regulation of buoyancy by zooplankton. Mar. Ecol. Prog. Ser. 263: 93-99.

Carmack, E., and Wassmann, P. 2006. Food webs and physicalbiological coupling on pan-Arctic shelves: unifying concepts and comprehensive perspectives. Progr. Oceanogr. 71: 446-477.
Chapelle, S. 1986. Aspects of phospholipid metabolism in crustaceans as related to changes in environmental temperatures and salinities. Comp. Biochem. Physiol. B, 84: 423-439.

Chen, F., and Marcus, N.H. 1997. Subitaneous, diapause, and delayed hatching eggs of planktonic copepods from the northern Gulf of Mexico: morphology and hatching success. Mar. Biol. 127: $587-597$.

Conover, R.J., and Siferd, T.D. 1993. Copepods in ice-covered seas - distribution, adaptations to seasonally limited food, metabolism, growth patterns and life cycle strategies in polar seas. J. Mar. Syst. 2: 1-41.

Dahms, H.U. 1995. Dormancy in the Copepoda - an overview. Hydrobiologia, 306: 199-211.

Dalsgaard, J., St. John, M., Kattner, G., Müller-Navarra, D., and Hagen, W. 2003. Fatty acid trophic markers in the pelagic marine environment. Adv. Mar. Biol. 46: 225-340.

Dickson, R.R., Osborn, T.J., Hurrel, J.W., Meincke, J., Blindheim, J., Ådloandsvik, B., Vinje, T., Alekseev, G., and Maslowski, W. 2000. The Arctic Ocean response to the North Atlantic Oscillation. J. Clim. 13: 2671-2696.

Dittmar, T., and Kattner, G. 2003. The biogeochemistry of the river and shelf ecosystem of the Arctic Ocean: a review. Mar. Chem. 83: $103-120$.

Drillet, G., Iversen, M.H., Sørensen, T.F., Ramløv, H., Lund, T., and Hansen, B.W. 2006. Effect of cold storage upon eggs of a calanoid copepod, Acartia tonsa (Dana) and their offspring. Aquaculture, 254: 714-729.

Ederington, M.C., McManus, G.B., and Harvey, H.R. 1995 Trophic transfer of fatty acids, sterols, and a triterpenoid alcohol between bacteria, a ciliate, and the copepod Acartia tonsa. Limnol. Oceanogr. 40: 860-867.

Edwards, M., and Richardson, A.J. 2004. Impact of climate change on marine pelagic phenology and trophic mismatch. Nature (London), 430: 881-884.

Falk-Petersen, S., Hagen, W., Kattner, G., Clarke, A., and Sargent, J. 2000. Lipids, trophic relationships, and biodiversity in Arctic and Antarctic krill. Can. J. Fish. Aquat. Sci. 57: 178-191.

Falk-Petersen, S., Timofeev, S., Pavlov, V., and Sargent, J.R. 2007. Climate variability and the effect on Arctic food chains. The role of Calanus. In Arctic-alpine ecosystems and people in a changing environment. Edited by J.B. Orbaek, T. Tombre, R. Kallenborn, E. Hegseth, S. Falk-Petersen, and A.H. Hoel. Springer Verlag, Berlin. pp. 147-166.

Farkas, T. 1979. Adaptation of fatty acid compositions to temperature - a study on planktonic crustaceans. Comp Biochem. Physiol. B, 64: 71-76.

Fevolden, S.E. 1980. Krill off Bouvetoya and in the southern Weddell Sea with a description of larval stages of Euphausia crystallorophias. Sarsia, 65: 149-162.

Flato, G.M., Boer, G.J., Lee, W.G., McFarlane, N.A., Ramsden, D., Reader, M.C., and Weaver, A.J. 2000. The Canadian centre for climate modelling and analysis global coupled model and its climate. Climate Dynamics, 16: 451-467.

Ghioni, C., Porter, A.E., Sadler, I.H., Tocher, D.R., and Sargent, J.R. 2001. Cultured fish metabolize octadecapentaenoic acid (all-cis $\Delta 3,6,9,12,15-18: 5$ ) to octadecatetraenoic acid (all-cis $\Delta 6,9,12,15-18: 4)$ via its 2-trans intermediate (trans $\Delta 2$, all-cis $\Delta 6,9,12,15-18: 5)$. Lipids, 36: 145-152.

Gradinger, R. 1995. Climate change and biological oceanography of the Arctic Ocean. Philos. Trans. R. Soc. Lond. A, 352: $277-$ 286.

Graeve, M., Kattner, G., and Hagen, W. 1994. Diet-induced changes in the fatty aicd composition of Arctic herbivorous 
copepods: experimental evidence of trophic markers. J. Exp. Mar. Biol. Ecol. 182: 97-110.

Graeve, M., Albers, C., and Kattner, G. 2005. Assimilation and biosynthesis of lipids in Arctic Calanus species based on ${ }^{13} \mathrm{C}$ feeding experiments with a diatom. J. Exp. Mar. Biol. Ecol. 317: $109-125$.

Grice, G.C., and Marcus, N.H. 1981. Dormant eggs of marine copepods. Oceanogr. Mar. Biol. Annu. Rev. 19: 125-140.

Hagen, W., and Auel, H. 2001. Seasonal adaptations and the role of lipids in oceanic zooplankton. Zoology, 104: 313-326.

Hagen, W., Kattner, G., and Graeve, M. 1993. Calanoides acutus and Calanus propinquus, Antarctic copepods with different lipid storage modes via wax esters or triacylglycerols. Mar. Ecol. Prog. Ser. 97: 135-142.

Hagen, W., Van Vleet, E.S., and Kattner, G. 1996. Seasonal lipid storage as overwintering strategy of Antarctic krill. Mar. Ecol. Prog. Ser. 134: 85-89.

Harvey, H.R., Eglington, G., O'Hara, S.C.M., and Corner, E.D.S. 1987. Biotransformation and assimilation of dietary lipids by Calanus feeding on a dinoflagellate. Geochim. Cosmochim. Acta, 51: 3031-3040.

Hirche, H.-J. 1996. Diapause in the marine copepod, Calanus finmarchicus - a review. Ophelia, 44: 129-143.

Hirche, H.-J., and Kattner, G. 1993. Egg production and lipid content of Calanus glacialis in spring: indication of a fooddependent and food-independent reproductive mode. Mar. Biol. 117: 615-622.

Hirche, H.-J., and Niehoff, B. 1996. Reproduction of the Arctic copepod Calanus hyperboreus in the Greenland Sea - field and laboratory observations. Polar Biol. 16: 209-219.

Iverson, S.J. 2004. Quantitative fatty acid signature analysis: a new method of estimating predator diet. Ecol. Monogr. 74: 211-235.

Jeffs, A.G., Nichols, P.D., and Bruce, M.P. 2001. Lipid reserves used by pueruli of the spiny lobster Jasus edwardsii in crossing the continental shelf of New Zealand. Comp. Biochem. Physiol. A, 129: 305-311.

Johannessen, O.M., Miles, M., and Bjørgo, E. 2002. The Arctic's shrinking sea ice. Nature (London), 376: 126-127.

Jónasdóttir, S.H. 1999. Lipid content of Calanus finmarchicus during overwintering in the Faroe-Shetland Channel. Fish. Oceanogr. 8: 61-72.

Katajisto, T. 2003. Development of Acartia bifilosa (Coepoda: Calanoida) eggs in the northern Baltic Sea with special reference to dormancy. J. Plankton Res. 25: 357-364.

Kattner, G., and Hagen, W. 1995. Polar herbivorous copepods different pathways in lipid biosynthesis. ICES J. Mar. Sci. 52: 329-335.

Kattner, G., Hagen, W., Graeve, M., and Albers, C. 1998. Exceptional lipids and fatty acids in the pteropod Clione limacina (Gastropoda) from both polar oceans. Mar. Chem. 61: 219-228.

Kattner, G., Graeve, M., Calcagno, J.A., Lovrich, G.A., Tatje, S., and Anger, K. 2003a. Lipid, fatty acid and protein utilisation during lecithotrophic larval development of Lithodes santolla (Molina) and Paralomis granulosa (Jacquinot). J. Exp. Mar. Biol. Ecol. 292: 61-74.

Kattner, G., Albers, C., Graeve, M., and Schnack-Schiel, S.B. $2003 b$. Fatty acid and alcohol composition of the small polar copepods, Oithona and Oncaea: indication on feeding modes. Polar Biol. 26: 666-671.

Lee, R.F., and Hirota, J. 1973. Wax esters in tropical zooplankton and nekton and the geographical distribution of wax esters in marine copepods. Limnol. Oceanogr. 18: 227-239.
Lee, R.F., Nevenzel, J.C., and Paffenhöfer, G.-A. 1970. Wax esters in marine copepods. Science (Washington, D.C.), 167: 1510 1511

Lee, R.F., Hirota, J., and Barnett, A.M. 1971. Distribution and importance of wax esters in marine copepods and other zooplankton. Deep-Sea Res. 18: 1147-1165.

Lee, R.F., Hagen, W., and Kattner, G. 2006. Lipid storage in marine zooplankton. Mar. Ecol. Prog. Ser. 307: 273-306.

Legendre, L., and Rivkin, R.B. 2005. Integrating functional diversity, food web processes, and biogeochemical carbon fluxes in a conceptual approach for modeling the upper ocean in a high$\mathrm{CO}_{2}$ world. J. Geophys. Res. 110: CO9S17. doi:10.1029/ 2004JC002530.

Lewis, R.W. 1970. The densities of three classes of marine lipids in relation to their possible role as hydrostatic agents. Lipids, 5: 151-152.

Lischka, S., and Hagen, W. 2007. Seasonal lipid dynamics of the copepods Pseudocalanus minutus (Calanoida) and Oithona similis (Cyclopoida) in the Arctic Kongsfjorden (Svalbard). Mar. Biol. 150: 445-454.

Loeb, V., Siegel, V., Holm-Hansen, O., Hewitt, R., Fraser, W. Trivelpiece, W., and Trivelpiece, S. 1997. Effects of sea-ice extent and krill or salp dominance on the Antarctic food web. Nature (London), 387: 897-900.

Marr, J.W.S. 1962. The natural history and geography of the Antarctic krill (Euphausia superba Dana). Discov. Rep. 32: 33-464.

Mayzaud, P. 1976. The occurrence and distribution of octadecapentaenoic acid in a natural plankton population. A possible food chain index. Lipids, 11: 858-862.

Mayzaud, P. 1997. Spatial and life-cycle changes in lipid and fatty acid structure of the Antarctic euphausiid Euphausia superba. In Antarctic communities: species, structure and survival. Edited by B. Battaglia, J. Valencia, and D.W.H. Walton. Cambridge University Press, Cambridge, UK. pp. 284-294.

Nielsen, P., Mortensen, J., Vismann, B., and Hansen, B.W. 2006. Physiological tolerance of marine calanoid copepod eggs to sulphide. Mar. Ecol. Prog. Ser. 328: 171-182.

Peterson, B.J., Holmes, R.M., McClelland, J.W., Vörösmarty, C.J., Lammers, R.B., Shiklomanov, A.I., Shiklomanov, I.A., and Rahmstorf, S. 2002. Increasing river discharge to the Arctic Ocean. Science (Washington, D.C.), 298: 2171-2172.

Phleger, C.F., Nichols, P.D., and Virtue, P. 1997. Lipids and buoyancy in Southern Ocean pteropods. Lipids, 32: 1093-1100.

Richardson, A.J., and Schoeman, D.S. 2004. Climate impact on plankton ecosystems in the Northeast Atlantic. Science (Washington, D.C.), 305: 1609-1613.

Rigby, S., and Milsom, C.V. 2000. Origins, evolution, and diversification of zooplankton. Annu. Rev. Ecol. Evol. Syst. 31: 293-313.

Roemmich, D., and McGowan, J. 1995. Climatic warming and the decline of zooplankton in the California Current. Science (Washington, D.C.), 267: 1324-1326.

Saito, H., and Kotani, Y. 2000. Lipids of four boreal species of calanoid copepods: origin of monoene fats of marine animals at higher trophic levels in the grazing food chain in the subarctic ocean ecosystem. Mar. Chem. 71: 69-82.

Sargent, J.R., and Henderson, R.J. 1986. Lipids. In The biological chemistry of marine copepods. Edited by E.D.S. Corner and S.C.M. O'Hara. Clarendon, Oxford, UK. pp. 59-108.

Sargent, J.R., Gatten, R.R., and McIntosh, R. 1977. Wax esters in the marine environment - their occurrence, formation, transformation and ultimate fates. Mar. Chem. 5: 573-584. 
Smetacek, V., and Nicol, S. 2005. Polar ocean ecosystems in a changing world. Nature (London), 437: 362-368.

Stillwell, W., and Wassall, S.R. 2003. Docosahexaenoic acid: membrane properties of a unique fatty acid. Chem. Phys. Lipids, 126: $1-27$.

Stübing, D. 2004. Lipid biochemistry of Antarctic euphausiids energetic adaptations and a critical appraisal of trophic markers. Ph.D. thesis, Department of Marine Zoology, University of Bremen, Germany.

Thibault, D., Head, E.J.H., and Wheeler, P.A. 1999. Mesozooplankton in the Arctic Ocean in summer. Deep-Sea Res. I, 46: 1391-1415.

Varpe, Ø., Fiksen, Ø., and Slotte, A. 2005. Meta-ecosystems and biological energy transport from ocean to coast: the ecological importance of herring migration. Oecologia, 146: 443-451.

Vinje, T. 1999. Barents Sea-ice edge variation over the past 400 years. In Proceedings of the Workshop on Sea-Ice Charts of the Arctic, Seattle, Washington, 5-7 August 1998. World Meteorological Organization, Geneva, Switzerland. WMO/TD No. 949. pp. 4-6.
Vinje, T. 2001. Fram strait ice fluxes and atmospheric circulation: 1950-2000. J. Clim. 14: 3508-3517.

Visser, A.W., and Jónasdóttir, S.H. 1999. Lipids, buoyancy and the seasonal vertical migration of Calanus finmarchicus. Fish. Oceanogr. 8: 100-106.

Vogt, N.B., and Knutsen, H. 1985. SIMCA pattern recognition classification of five infauna taxonomic groups using non-polar compounds analysed by high resolution gas chromatography. Mar. Ecol. Prog. Ser. 26: 145-156.

Wang, G., Jiang, X., Wu, L., and Li, S. 2005. Differences in the density, sinking rate and biochemical composition of Centropages tenuiremis (Copepoda: Calanoida) subitaneous and diapause eggs. Mar. Ecol. Prog. Ser. 288: 165-171.

Wanless, S., Harris, M.P., Redman, P., and Speakman, J.R. 2005. Low energy values of fish as a probable cause of a major seabird breeding failure in the North Sea. Mar. Ecol. Prog. Ser. 294: 1-8.

Zenkevich, L. 1963. Biology of the seas of the USSR. Georg Allen and Unwin, London, UK. 